\title{
Wujud dan Makna Implikatur dalam Humor Miss Dakem Karawang serta Alternatifnya sebagai Bahan Ajar Teks Anekdot di SMA Kelas X
}

\author{
Ria Sonia \\ Program Studi Pendidikan Bahasa dan Sastra Indonesia \\ Universitas Singaperbangsa Karawang \\ Email: riasonia405@gmail.com \\ Oding Supriadi \\ Program Studi Pendidikan Bahasa dan Sastra Indonesia \\ Universitas Singaperbangsa Karawang \\ Email: odingsupr17@gmail.com \\ Sahlan Mujtaba \\ Program Studi Pendidikan Bahasa dan Sastra Indonesia \\ Universitas Singaperbangsa Karawang \\ Email: sahlan.mujtaba@fkip.unsika.ac.id
}

APA Citation: Sonia, R., Supriadi, O., \& Mujtaba, S. (2021). Wujud dan Makna Implikatur dalam Humor Miss Dakem Karawang serta Alternatifnya sebagai Bahan Ajar Teks Anekdot di SMA Kelas X. Silampari Bisa: Jurnal Penelitian Pendidikan Bahasa Indonesia, Daerah, dan Asing, 4(2), 279-290. https://doi.org/10.31540/silamparibisa.v4i2.1326

\begin{abstract}
Abstrak
Penelitian ini bertujuan untuk mendeskripsikan wujud dan makna implikatur dalam humor Miss Dakem Karawang. Jenis penelitian yang digunakan dalam penelitian ini adalah deskriptif kualitatif. Subjek dari penelitian ini adalah tuturan dalam humor Miss Dakem Karawang. Sementara untuk objek penelitian ini adalah wujud dan makna implikatur dalam humor Miss Dakem Karawang. Pengumpulan data penelitian ini dilakukan dengan dokumentasi yaitu teknik simak, mencatat hal-hal penting dengan menggunakan tabel data. Teknik ini dilakukan dengan menyimak dengan teliti sebuah tuturan yang ada dalam video humor Miss Dakem Karawang. Humor Miss Dakem Karawang memiliki 1 wujud implikatur dan menghasilkan sebanyak 9 tuturan percakapan. Sedangkan untuk makna implikatur dalam penelitiian ini terdapat 5 makna yaitu, asertif, direktif, komisif, ekspresif, dan deklaratif terdapat 12 tuturan percakapan yang mengandung makna implikatur dalam Miss Dakem Karawang. Hasil penelitian ini diharapkan dapat dimanfaatkan sebagai bahan ajar teks anekdot dalam bentuk handout.
\end{abstract}

Kata kunci: wujud dan makna implikatur, humor Miss Dakem Karawang, bahan ajar teks anekdot 
Ria Sonia, Oding Supriadi, Sahlan Mujtaba

Bentuk dan Makna Implikatur dalam Humor Miss Dakem Karawang serta Alternatifnya sebagai Bahan Ajar Teks Anekdot di SMA Kelas X

\title{
Form and Meaning of Implicature in Miss Dakem Karawang Humor and its Alternatives as Anecdotal Text Teaching Materials in Class X High School
}

\begin{abstract}
This study aims to describe the form and meaning of implicatures in Miss Dakem Karawang's humor. The type of research used in this research is descriptive qualitative. The subject of this research is the humorous utterances of Miss Dakem Karawang. Meanwhile, the object of this research is the form and meaning of implicature in Miss Dakem Karawang's humor. This research data collection was carried out by means of documentation, namely listening techniques, noting important things using data tables. This technique is done by listening carefully to a speech in the Miss Dakem Karawang humor video. Miss Dakem Karawang humor has 1 form of implicature and produces 9 conversational utterances. As for the meaning of implicature in this study, there are 5 meanings, namely, assertive, directive, commissive, expressive, and declarative, there are 12 conversational utterances containing implicature meaning in Miss Dakem Karawang. The results of this study are expected to be used as teaching materials for anecdotal texts in the form of handouts.
\end{abstract}

Keywords: form and meaning of implicature, Miss Dakem Karawang humor, anecdotal text teaching materials

\section{A. Pendahuluan}

Humor merupakan suatu sikap yang cenderung dilakukan untuk membangkitkan suatu rasa gembira dan memicu mitra tutur merensposns dengan gelak tawa (Sekarwati, 2018:138; Abdullah \& Nurhidayah (2019:115). Artinya humor adalah adanya sesuatu yang berbeda dan unik diberikan oleh seseorang sehingga melahirkan unsur lucu atau menggelikan. Dalam humor mengandung banyak makna yang secara pragmatik menarik untuk dianalisis karena memiliki ciri khas dibandingkan dengan wacana lainnya.

Edi (2018:11) menjelaskan pragmatik merupakan bagian ilmu bahasa yang menyoroti tentang makna bahasa dalam penggunaannya yang terikat oleh konteks. Artinya salah satu cabang ilmu bahasa yang mengkaji mengenai makna sesuai dengan konteks yang ada yaitu pragmatik. Kajian makna suatu wacana bisa dilihat dari kajian implikaturnya.

Implikatur merupakan aspek yang sangat penting yang harus dipahami baik oleh penutur maupun mitra tutur (Budiyanto, 2013). Hal ini dikarenakan sebelum penutur menyampaian tuturan tidak langsung, maka penutur harus memiliki dugaan bahwa mitra tutur mengerti dengan apa yang dituturkan. Begitu juga sebaliknya dengan mitra tutur, harus berusaha mencermati dan menyelami maksud yang terkandung dalam tuturan penutur, karena tidak selamanya maksud penutur tereksplisitkan. Oleh sebab itu, mitra tutur dituntut mengetahui konteks tutur (Edi, 2019:21).

Sedangkan menurut Grice (dalam Isnaniah, 2018:135) dan Andriani (2021) implikatur sebagai implikasi makna yang tersirat dalam suatu tuturan yang disertai konteks, meskipun makna itu bukan merupakan bagian atau pemenuh dari apa yang dituturkan. Oleh karena itu, implikatur dapat dipahami melalui jalur konteksnya. Artinya implikatur merupakan makna tersirat di dalam tuturan, untuk 
memahami makna tidak langsung tersebut mitra tutur harus memahami terlebih dahulu konteks yang melatar belakangi tuturan tersebut.

Menurut Grice (dalam Wahyuningsih \& Rafli, 2017), menyatakan bahwa implikatur terbagi menjadi 2 yaitu: implikatur konvensional dan implikatur non konvensional. Implikatur konvensional adalah implikatur yang diperoleh langsung, bukan dari prinsip percakapan. Semua orang tentunya sudah mengetahui tentang maksud atau pengertian sesuatu hal tertentu.' Artinya di dalam implikatur konvensional mitra tutur sudah mengetahui maksud atau makna dari tuturan tersebut. Kemudian, implikatur percakapan muncul akibat pelanggaran dari salah satu empat maksim. Yaitu, maksim kuantitas, maksim kualitas, maksim relavansi dan maksim cara. Adanya implikatur percakapan disebabkan oleh pelanggaran empat maksim, yang dimaksud dengan maksim yaitu prinsip atau aturan yang harus dipahami ke dua belah pihak antara penutur dan mitra tutur.

Maksim merupakan aturan penutur dalam suatu tuturan yang wajar. Grice dalam (Nugroho, (2020), membedakan maksim dalam 5 jenis yaitu: 1) maksim kuantitas, yaitu bahwa ujaran yang wajar dalam komunikasi ialah yang mengungkapkan hal-hal yang secukupnya; 2) maksim pelaksanaan tidak berlebihan dan tidak kurang untuk menyampaikan informasi; 3) maksim kualitas, yaitu apa yang diungkapkan itu benar; 4) maksim relavansi, bahwa apa yang diungkapkan itu relevan dengan situasi yang ada dalam dan sekitar berbahasa; dan 5) maksim cara, bahwa apa yang diungkapkan ini adalah cukup jelas dan tidak berdwimakna.

Menurut Tarigan (2015:42) membagi makna implikatur menjadi lima yaitu: asertif, direktif, komisif, ekspresif, dan deklaratif. Asertif adalah melibatkan pembicara pada kebenaran preposisi yang diekspresikan, misalnya: menyatakan, memberitahukan, menyarankan, membanggakan, mengeluh, menuntut." Artinya asertif merupakan tindak tutur yang membawa nilai benar atau salah berdasarkan sisi keyakinan dari si penutur. Direktif dimaksudkan untuk menimbulkan beberapa efek melalui tindakan sang penyimak. Misalnya, memesan, memerintahkan, memohon, meminta, menyarankan, menasihatkan. Artinyadirektif merupakan tuturan yang diujarkan oleh penutur dengan tujuan agar mitra tutur berkenan melakukan tindakan yang sesuai dengan yang dituturkan.

Kemudian, komisif melibatkan pembicara pada tindakan yang akan datang, misalnya: menjanjikan, bersumpah, menawarkan, memanjatkan doa." Artinya komisif adalah tindak tutur yang berhubungan dengan dengan kewajiban yang mengikat, yang dituturkan penutur, serta harus dilaksanakan sesuai dengan tuturannya. Sedangkan implikatur ekspresif mempunyai fungsi untuk mengekspresikan, mengungkapkan, atau memberitahukan sikap psikologis sang pembicara menuju suatu pernyataan keadaan. Misalnya: mengucapkan terima kasih, mengucapkan selamat, memaafkan, mengampuni, menyalahkan, memuji, menyatakan belasungkawa dan sebagainya." Artinya ekspresif untuk mempresentasikan maksud, gagasan dari keadaan psikologis penutur.

Berbeda dengan implikatur deklaratif yaitu bila formasinya berhasil akan menyebabkan korespondensi yang baik antara isi proposional dengan realitas. misalnya: menyerahkan diri, memecat, membebaskan, memberi nama, menamai, mengucilkan, mengangkat, menunjuk, menentukan, menjatuhkan hukuman, memvonis, dan sebagainya. Artinya direktif merupakan penyampaian makna yang baik antara penutur dan mitra tutur. 
Analisis mengenai implikatur dalam humor Miss Dakem Karawang telah beberapa kali dilakukan. Beberapa di antaranya adalah penelitian yang dilakukan oleh, Wahyuningsih \& Rafli (2017), Pudyastuti \& Zamzani (2019), Nurfaizah \& Rustono (2017), Yuliansyah (2019), dan Rahayu \& Markhamah (2018). Wahyuningsih \& Rafli (2017) dalam artikelnya Implikatur Percakapan dalam Stand Up Comedy 4 membahas mengenai jenis implikatur, sifat implikatur dan maksim kerjasama dalam Stand Up Comedy 4. Hasil penelitian ini adalah jenis implikatur di dalam Stand Up Comedy 4 ada 2 yaitu implikatur percakapan dan implikatur konvensional. Sifat implikatur yang ada dalam Stand Up Comedy 4 meliputi daya batal, daya pisah dan daya kalkulabilitas. Maksim kerja sama yang ada dalam Stand Up Comedy 4 yaitu, maksim kualitas, maksim kuantitas, maksim cara dan maksim relavansi.

Penelitian ini berbeda dengan penelitian oleh Wahyuningsih \& Rafli (2017) bahwa subjek penelitian dalam penelitian ini yaitu tuturan dalam humor Miss Dakem Karawang sedangkan penelitian oleh Wahyuningsih \& Rafli (2017) subjeknya adalah percakapan dalam Stand Up Comedy 4. Penelitian tentang pragmatik di dalam rangka tesis telah dilakukan oleh Pudyastuti \& Zamzani (2019), tesis yang berjudul Implikatur Percakapan dalam Proses Pembelajaran Bahasa Indonesia di SMA Negeri 4 Yogyakarta karya Pudyastuti \& Zamzani (2019). Masalah yang diteliti dalam Pudyastuti \& Zamzani (2019) ini meliputi 3 masalah, yaitu (1) apakah jenis implikatur percakapan dalam proses tuturan guru pada proses pembelajaran Bahasa Indonesia di SMK Negeri 4 Yogyakarta (2) Apa Fungsi Implikatur percakapan dalam tuturan guru pada proses pembelajaran Bahasa Indonesia di SMK Negeri 4 Yogyakarta (3) apakah alasan penggunaan implikatur percakapan dalam tuturan guru yang terjadi dalam proses pembelajaran Bahasa Indonesia di SMK Negeri 4 Yogyakarta. Hasil penelitian ini berupa (1) jenis implikatur percakapan yakni, implikatur percakapan umum, dan implikatur percakapan khusus (2) fungsi implikatur yaitu komunikatif, asertif, ekspresif, direktif, dan komisif.

Hasil penelitian ini menunjukan bahwa subjek yang digunakan yaitu tuturan dalam humor Miss Dakem Karawang sedangkan penelitian oleh Pudyastuti \& Zamzani (2019) subjek penelitiannya yaitu Percakapan dalam Proses Pembelajaran Bahasa Indonesia. Selanjutnya, Nurfaizah \& Rustono (2017) meneliti Implikatur dalam Wacana Stand Up Comedy Indonesia Sesi 4 Dodit Mulyanto di Kompas Tv. Masalah yang diteliti dalam penelitian ini yaitu (1) wujud implikatur apasajakah yang terdapat dalam wacana Stand Up Comedy Indonesia Sesi 4 Dodit Mulyanto di Kompas Tv? (2) sumber implikatur apasajakah yang terdapat dalam wacana Stand Up Comedy Indonesia Sesi 4 Dodit Mulyanto di Kompas Tv. Hasil yang dilakukan dalam penelitian ini yaitu prinsip percakapan yang meliputi prinsip kerja sama terdapat 4 bidal yaitu, bidal kuantitas, bidal kualitas, bidan relevansi, bidal cara. Prinsip kesantunan meliputi enam bidal yaitu, bidal ketimbangrasaan, bidal kemurah hatian, bidal keperkenaan, bidal kerendah hatian, bidal kesetujuan, bidal kesimpatian.

Hasil penelitian ini menunjukan bahwa metode penelitian yang digunakan oleh Nurfaizah \& Rustono (2017) sama yaitu, metode penelitian kualitatif deskriptif. Namun, subjek penelitiannya berbeda. Kemudian, Yuliansyah (2019), judul penelitian ini yaitu Jenis dan Fungsi Implikatur pada Buku Tuhan Pun Berpuasa

Silampari Bisa: Jurnal Penelitian Pendidikan Bahasa Indonesia, Daerah, dan Asing Vol. 4, No. 2, 2021 
Ria Sonia, Oding Supriadi, Sahlan Mujtaba

Bentuk dan Makna Implikatur dalam Humor Miss Dakem Karawang serta Alternatifnya sebagai Bahan Ajar Teks Anekdot di SMA Kelas $X$

Karya Emha Ainun Nadjib. Hasil yang ditemukan dalam penelitian ini adalah mendeskripsikan jenis dan fungsi implikatur yang terkandung pada buku Tuhan Pun Berpuasa karya Emha Ainun Nadjib dan maksud-maksud implikatur berdasarkan pengetahuan, konteks dan tuturan. terdapat 2 jenis implikatur dalam penelitian ini yaitu (1) implikatur konvensional, terdapat beberapa fungsi meliputi, fungsi deklaratif, fungsi konvensional imperatif, fungsi konvensional introgatif, fungsi konvensional ekslamatif; dan (2) implikatur percakapan, terdapat beberapa fungsi yaitu, deklaratif, Imperatif introgatif, eklamatif.

Hasil penelitian ini menunjukan bahwa, metode yang digunakan sama yaitu metode penelitian kualitatif deskriptif. Hasil yang ditemukan oleh Yuliansyah (2019), yaitu mengenai implikatur konvensional. Sedangkan penelitian ini mendapatkan hasil implikatur percakapan. Kemudian, Rahayu \& Markhamah (2018) dalam skripsinya yang berjudul Implikatur Konvensional dalam Acara Stand Up Comedy Indonesia Seasone 7 di Statiun Kompas TV. Dalam penelitian ini terdapat beberapa masalah yang diteliti (1) memaparkan maksud tuturan yang mengandung implikatur konvensional pada acara Stand Up Comedy Indonesia Seasone 7. (2) Mendeskripsikan jenis tuturan yang mengandung implikatur konvensional pada acara Stand Up Comedy Indonesia Seasone 7. (3) Memaparkan fungsi tuturan yang mengandung implikatur konvensional pada acara Stand Up Comedy Indonesia Seasone 7. Dalam penelitian ini ditemukan maksud tuturan yang mengandung implikatur yaitu, maksud kehidupan sosial sehari-hari atau bermasyarakat, maksud kritik terhadap pihak tertentu, maksud tidak ingin mengalami kondisi yang sekarang, maksud mengakui kekurangan pribadi, maksud pengharapan kondisi lebih baik, maksud teknologi, maksud kondisi daerah Indonesia Timur, maksud pendidikan di Indonesia. Terdapat juga jenis tuturan yang mengandung implikatur konvensional pada acara Stand Up Comedy Indonesia Seasone 7 meliputi, tuturan deklaratif (pernyataan), Tuturan pernyataan kehidupan pribadi, tuturan pernyataan tempat tinggal, tuturan pernyataan pendapat pribadi, tuturan pernyataan keinginan, dan jenis tuturan introgatif, tuturan kalimat tanya sindirian, tuturan kaimat tanya makian. Fungsi implikatur konvensional yang terkandung dalam penelitian ini meliputi, implikatur yang berfungsi asertif yang meliputi menyatakan, tuturan menyatakan penderitaan, tuturan menyatakan hinaan, tuturan menyatakan pendapat pribadi, menyatakan daerah atau lingkungan, tuturan menyatakan pendapat pribadi, mengeluh, tuturan mengeluh keadaan pribadi, tuturan mngeluh sindiran. Implikatur berfungsi ekspresif yaitu, menyindir, tuturan menyindir kebiasaan, tuturan menyindir pemerintah, tuturan menyindir hinaan. Implikatur berfungsi direktif yaitu, memohon.

Dalam penelitian ini sama-sama menganalisis humor dengan menggunakan metode penelitian kualitatif. Namun subjek penelitian oleh Rahayu \& Markhamah (2018) berbeda dengan subjek penelitian ini yaitu tuturan Stand Up Comedy Indonesia Seasone 7, sedangan penelitian ini yaitu tuturan dalam humor Miss Dakem Karawang.

\section{B. Metode Penelitian}

Penelitian ini adalah penelitian analisis wacana dengan menggunakan metode deskriptif kualitatif. Dengan metode deskriptif kualitatif harapannya dapat menggambarkan wujud dan makna implikatur dalam humor Miss Dakem Karawang dan subjek penelitiannya adalah tutran yang terdapat dalam humor tersebut. Objek 
Ria Sonia, Oding Supriadi, Sahlan Mujtaba

Bentuk dan Makna Implikatur dalam Humor Miss Dakem Karawang serta Alternatifnya sebagai Bahan Ajar Teks Anekdot di SMA Kelas X

dalam penelitian ini adalah wujud dan makna implikatur yang terdapat dalam w humor Miss Dakem Karawang.

Teknik penelitian ini adalah dokumentasi. Data yang diperlukan dalam penelitian ini yaitu tuturan kalimat yang mengandung implikatur dalam humor Miss Dakem Karawang. Pada tahap pengumpulan data, peneliti mencari tuturan humor Miss Dakem Karawang yang mengandung unsur implikatur pada sosial media youtube kemudian tuturan humor tersebut ditranskrip kedalam bentuk tulisan.

Instrumen penelitian menurut Arikunto (2006:149) merupakan alat bantu bagi penulis dalam mengumpulkan data. Arikunto (2006:149) menyebutkan bahwa instrumen penelitian adalah alat atau fasilitas yang digunakan oleh penulis dalam mengumpulkan data agar pekerjaannya lebih mudah dan hasilnya lebih baik, dalam arti lebih cermat, lengkap dan sistematis, sehingga mudah diolah.

Instrumen dalam penelitian ini adalah penulis sendiri, instrumen penelitian dilakukan dengan studi dokumentasi dibantu dengan tabulasi data penelitian. Instrumen dalam penelitian menggunakan kartu data yaitu berupa tabel wujud dan makna implikatur dalam humor Miss Dakem Karawang. Teknik analisis data dilakukan dengan cara reduksi data, penyajian data, penarikan kesimpulan atau verifikasi.

\section{Hasil Penelitian dan Pembahasan}

\section{Hasil Penelitian}

Penelitian ini menggunakan tuturan sebagai subjek penelitian, yang mana peneliti meneliti homor Miss Dakem Karawang yang berjudul "Miss Dakem bahasa luar negerinya keluar" yang berdurasi 28.57 menit, ditemukan wujud dan makna implikatur sebanyak 21 tuturan.

\section{a. Wujud Implikatur dalam Humor Miss Dakem Karawang}

Wujud implikatur terbagi menjadi 2 yaitu implikatur konvensional dan implikatur percakapan. Wujud implikatur yang ditemukan dalam humor Miss Dakem Karawang yaitu implikatur percakapan saja. Berikut hasil yang diperoleh peneliti setelah meneliti wujud implikatur dalam humor Miss Dakem Karawang. Terdapat 9 wujud implikatur percakapan dalam humor Miss Dakem Karawang.

\section{b. Makna Implikatur dalam humor Miss Dakem Karawang}

Makna implikatur terbagi menjadi 5 yaitu, asertif, direktif, komisif, ekspresif dan deklaratif. Berikut hasil yang diperoleh peneliti setelah melakukan penelitian. Makna implikatur dalam humor Miss Dakem Karawang dalam penelitian ini terdapat 12 tuturan.

\section{Pembahasan}

\section{a. Wujud Implikatur dalam Humor Miss Dakem Karawang}

Pada penelitian ini menunjukan bahwa wujud Implikatur dalam Humor Miss Dakem Karawang Implikatur memiliki 2 wujud yaitu konvensional dan percakapan. Namun, dalam humor Miss Dakem Karawang hanya terdapat wujud implikatur percakapan saja. Hal ini berbeda dengan hasil penelitian oleh Wahyuningsih \& Rafli (2017) bahwa subjek penelitian nya yaitu Percakapan dalam Stand Up Comedy 4. Hal ini juga berbeda dengan penelitian yang dilakukan oleh Pudyastuti 
Ria Sonia, Oding Supriadi, Sahlan Mujtaba

Bentuk dan Makna Implikatur dalam Humor Miss Dakem Karawang serta Alternatifnya sebagai Bahan Ajar Teks Anekdot di SMA Kelas X

\& Zamzani (2019) bahwa masalah yang diteliti berbeda. Penelitian ini sama dengan penelitian yang dilakukan oleh Nurfaizah \& Rustono (2017) yaitu samasama menganalisis wujud implikatur percakapan. Penelitian ini juga berbeda dengan yang dilakukan oleh Rahayu \& Markhamah (2018) bahwa data yang ditemukan pada penelitian ini yaitu implikatur percakapan sedangkan oleh Rahayu \& Markhamah (2018) implikatur konvensional.

\section{Pelanggaran Maksim Kuantitas}

Konteks 1: Percakapan terjadi ketika Miss Dakem mendoakan mempelai wanita dan pria agar mempunya momongan yang ganteng dan cantik.

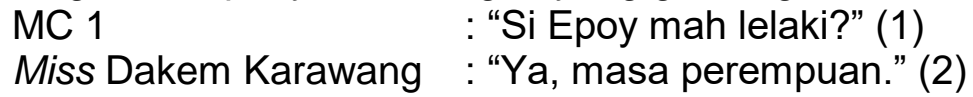

Pelanggaran maksim kuantitas pada percakapan di atas terdapat pada kutipan ke (2) yang dituturkan oleh Miss Dakem Karawang, yaitu "ya, masa perempuan". Jawaban yang dilontarkan oleh Miss Dakem Karawang lebih panjang dari informasi yang dibutuhkan oleh mc 1. Oleh karena itu tuturan Miss Dakem Karawang tersebut melanggar maksim kuantitas. Pelanggaran maksim kuantitas ini muncul karena adanya implikatur percakapan. Implikatur yang muncul akibat pelanggaran tersebut antara lain sebagai berikut: (1) Miss Dakem Karawang ingin memberitahu mc 1 bahwa Epoy merupakan laki-laki bukan perempuan.

\section{Pelanggaran Maksim Kualitas}

Konteks 1: Tuturan terjadi di panggung antara Miss Dakem Karawang dan mc 1 MC 1 : "Kalau si Epoy teh siapa?"

Miss Dakem Karawang : "Ada kembaran saya si Epoy mah ganteng kaya leminho."

Pelanggaran maksim kualitas terdapat pada kutipan nomor (2) yang dituturkan oleh Miss Dakem Karawang. Dalam maksim kualitas, penutur diharapkan memberi kontribusi percakapan yang dia yakini kebenarannya dan sesuai fakta sebenarnya. Tuturan Miss Dakem Karawang yang menyatakan Epoy mah ganteng kaya Leminho merupakan pelanggaran maksim kualitas karena apa yang dia nyatakan tidak memiliki nilai kebenaran atau dia berbohong, namun jika tuturan Miss Dakem Karawang mengakui si Epoy adalah dirinya sendiri maka Miss Dakem Karawang tidak melanggar maksim kualitas. Adanya pelanggaran maksim tersebut adalah Miss Dakem Karawang bersih keras bahwa si Epoy merupakan saudara kembarnya yang berjenis kelamin laki-laki.

Konteks 2: percakapan terjadi ketika Miss Dakem Karawang dan bunda Ebreg sedang adu mulut.

MC 1

Miss Dakem Karawang

MC 1

Pelanggaran maksim kuantitas pada percakapan di atas terdapat pada kutipan ke (2) yang dituturkan oleh Miss Dakem Karawang. Yaitu, "Ia, punya ibu latahan. Kemarin digigit anjing, malah anjingnya digigit lagi sama dia." Jawaban yang diberikan oleh Miss Dakem Karawang lebih panjang dari informasi yang dibutuhkan oleh mc 1. Oleh karena itu tuturan Miss Dakem Karawang melanggar maksim kuantitas. Pelanggaran maksim kuantitas ini muncul karena adanya implikatur

Silampari Bisa: Jurnal Penelitian Pendidikan Bahasa Indonesia, Daerah, dan Asing Vol. 4, No. 2, 2021 
Ria Sonia, Oding Supriadi, Sahlan Mujtaba

Bentuk dan Makna Implikatur dalam Humor Miss Dakem Karawang serta Alternatifnya sebagai Bahan Ajar Teks Anekdot di SMA Kelas $X$

percakapan. Implikatur yang muncul karena pelanggaran tersebut yaitu: (1) Miss Dakem Karawang ingin memberi tahu kalau ibunya latahan.

Konteks 3: Percakapan terjadi ketika Miss Dakem Karawang baru muncul di atas panggung.

MC 1

: "Lu mau maen bola?" (1)

Miss Dakem Karawang : "Anda menghina? saya kemaren baru pulang dari eropa jangan sirik" (2)

Pelanggaran maksim kualitas pada percakapan di atas terdapat pda kutipan (2) "Anda menghina? saya kemaren baru pulang dari eropa jangan sirik" jawaban yang diberikan Miss Dakem Karawang lebih panjang dairi informasi yang dibutuhkan oleh mc 1. Oleh karena itu tuturan Miss Dakem Karawang melanggar maksim kuantitas. Pelanggaran maksim kuantitas ini muncul karena adanya implikatur percakapan. Implikatur yang muncul karena pelanggaran tersebut yaitu:

(1) Miss Dakem Karawang menduga kalau mic 1 menghina penampilannya seperti orang mau main bola.

\section{Pelanggaran Maksim Hubungan}

Konteks 1: Pecakapan terjadi ketika Miss Dakem Karawang memberitahu kalau dia berbohong terhadap ibunya bahwa dia kerja di bank.

MC $1 \quad$ : "Bank apa lu teh?" (1)

Miss Dakem Karawang : "Bank mari bank mampir bank" (2)

Percakapan tersebut melibatkan Miss Dakem Karawang dan mc 1. Topik pembicaraannya adalah menanyakan nama bank yang menjadi tempat kerja Miss Dakem Karawang. Situasi terjadi sesaat Miss Dakem Karawang dan bunda Ebreg. Percakapan Miss Dakem Karawang dan mc 1 tidak luput dari melanggar maksim hubungan/ relavansi. Akibat dari pelanggaran maksim hubungan inilah muncul maksud implikatur. Pada percakapan jawaban Miss Dakem Karawang (2) melanggar maksim hubungan dari pertanyaan mc 1. Mc 1 menanyakan nama bank, tetapi Miss Dakem Karawang tidak menjawab pertanyaan mc 1 tersebut. Tuturan (2) "Bank mari bank mampir bank". Percakapan yang muncul karena maksim tersebut yaitu: (1) Miss Dakem Karawang menjawab pertanyaan mc 1 dengan diplesetin ke jawaban yang lain.

\section{Pelanggaran Maksim Cara}

Konteks 1: Percakapan terjadi di atas panggung

$$
\begin{array}{ll}
\text { MC } 1 & \text { : "Eropa tuh di mana neng?" (1) } \\
\text { Miss Dakem Karawang } & \text { : "Eropa?" (2) } \\
\text { MC } 1 & \text { : "Sebelah mana Johar?" (3) } \\
\text { Miss Dakem Karawang } & \text { : "Ga tau" (4) }
\end{array}
$$

Tuturan pada percakapan ini memiliki kejelasan yang rendah, apalagi jika tuturan tersebut tanpa konteksnya. Karena kadar kejelasan yang rendah, maka dengan sendirinya kadar keambiguan tuturan tersebut akan tinggi. Tuturan mic 1 pada percakapan (3) yang berbunyi "Sebelah mana johar" tidak memberikan penjelasan apa yang sebenarnya diminta oleh Miss Dakem Karawang. Pelanggaran maksim cara ini muncul karena adanya implikatur percakapan. Implikatur yang muncul akibat pelanggaran maksim cara pada tuturan (3) tersebut 
Ria Sonia, Oding Supriadi, Sahlan Mujtaba

Bentuk dan Makna Implikatur dalam Humor Miss Dakem Karawang serta Alternatifnya sebagai Bahan Ajar Teks Anekdot di SMA Kelas X

antara lain sebagai berikut: (1) mc 1 tidak menjawab pertanyaan awal Miss Dakem Karawang.

\section{b. Makna Implikatur dalam Humor Miss Dakem Karawang}

Selain wujud implikatur, yang akan dikaji pada penelitian ini yaitu makna implikatur dalam humor Miss Dakem Karawang terdapat 5 fungsi implikatur yaitu, asertif, direktif, komisif, ekspresif dan deklaratif. Berikut ini akan dibahas terkait hasil yang telah ditemukan hasil analisis makna implikatur dalam humor Miss Dakem Karawang. Pembahasan tersebut yaitu sebagai berikut:

\section{Makna Implikatur Asertif}

\section{Penggalan percakapan 1:}

MC 1

Miss Dakem Karawang : "Iya, si Epoy mah lalaki masa perempuan" (2)

Berdasarkan penggalan percakapan tersebut tuturan Miss Dakem Karawang pada percakapan (2) "iya, si Epoy mah lalaki masa perempuan." termasuk dalam makna implikatur asertif karena termasuk dalam kalimat yang menyatakan. Dalam arti bahwa, kata "iya, si Epoy mah lalaki masa perempuan"memiliki makna menyatakan kalau memang si Epoy laki-laki sesuai dengan pertanyaan mc 1 pada percakapan (1) yaitu, "Si Epoy mah lelaki?".

\section{Makna Implikatur Direktif \\ Penggalan Percakapan 1: \\ MC 1 \\ "Ada lagunya ya?" (1) \\ Miss Dakem Karawang : "Ada" (2) \\ MC 1 : "Gimana coba neng" (3) \\ Miss Dakem Karawang : "Bencong bodong, bencong bodong korban egonya lelaki" (4)}

Berdasarkan penggalan percakapan di atas, tuturan mc 1 pada percakapan (3) "gimana coba neng" memiliki makna direktif. Kata "gimana coba neng" termasuk ke dalam kalimat memerintah, untuk memerintahkan Miss Dakem Karawang menyanyikan sebuah lagu yang ditanyakan mc 1 pada percakapan (1) yaitu "ada lagunya ya?".

\section{Makna Implikatur Komisif}

Penggalan Percakapan 1:

Miss Dakem Karawang : "Assalamualaikum wr. wb, mudah-mudahan pengantin menjadi keluarga SMW aamiin, biar bahagia selamanya, cepet-cepet punya keturunan

Penonton yang cantiknya kaya akem, gantengnya kaya si epoy." (1)

Berdasarkan penggalan percakapan di atas, tuturan Miss Dakem Karawang memiliki makna komisif yaitu memanjatkan doa. Tuturan tersebut memanjatkan doa agar pengantin menjadi keluarga yang sakinah mawadah dan warahmah, serta memiliki putra dan putri yang cantik dan ganteng. 
Ria Sonia, Oding Supriadi, Sahlan Mujtaba

Bentuk dan Makna Implikatur dalam Humor Miss Dakem Karawang serta Alternatifnya sebagai Bahan Ajar Teks Anekdot di SMA Kelas X

\section{Makna Implikatur Ekspresif \\ Penggalan Percakapan 1:}

Miss Dakem Karawang : Saya mah saya punya suami agak bener bu, enggak kaya kemaren saya omeli-omelin bae (1)

MC 1

: "Alhamdulillah" (2)

Miss Dakem Karawang

"Eh sekarang mah ada kemauan, kemarin ge ngojek terus kadang rame, kadang sepi, kadang ga dapet pisan" (3)

MC 1 : "la biarin ga apa-apa" (4)

Berdasarkan penggalan di atas, tuturan Miss Dakem Karawang (3) memiliki makna implikatur ekspresif memuji. Miss Dakem Karawang memuji suaminya yang sekarang-sekarang ini ada kemauan untuk kerja menjadi tukang ojek.

\section{Makna Implikatur Deklaratif \\ Penggalan Percakapan 1: \\ MC 2}

: "Perkenalan ke orang sini Kem" (1)

Miss Dakem Karawang : "Pake lagu ah" (2)

Berdasarkan penggalan percakapan di atas, tuturan Miss Dakem Karawang 2 memiliki makna deklaratif menentukan. Artinya Miss Dakem Karawang menentukan keinginannya ketika disuruh oleh MC 1 untuk memperkenalkan diri, ia ingin memperkenalkan dirinya dengan lagu.

\section{c. Pemanfaatan Implikatur dalam Humor Miss Dakem Karawang sebagai Bahan Ajar Teks Anekdot}

Penulis memanfaatkan hasil penelitian implikatur dalam humor Miss Dakem Karawang ini menjadi bahan ajar teks anekdot untuk siswa SMA kelas X. Materi ini penulis sajikan ke dalam bentuk handout dengan berpedoman pada kompetensi dasar dan indikator pencapaian kompetensi materi teks anekdot agar materi yang disajkan sesuai dengan kebutuhan. Handout tersebut tidak hanya berisi hasil analisis implikatur dalam humor Miss Dakem Karawang saja, melainkain materi lainnya yang termasuk ke dalam kompetensi dasar tersebut.

\section{Simpulan}

Berdasarkan hasil penelitian keseluruhan video Humor Miss Dakem Karawang yang penulis teliti, terdapat sebanyak 21 implikatur yang peneliti temukan. Wujud implikatur dari keseluruhan data tersebut tidak semuanya berbeda. Terdapat 1 wujud implikatur diantaranya implikatur percakapan yang meliputi maksim, kuantitas, maksim kualitas, maksim hubungan, dan maksim cara. Dari video humor Miss Dakem Karawang yang berdurasi 28.57 menit, terdapat lima makna implikatur, yakni asertif, direktif, komisif, ekspresif dan deklaratif. Terdapat sebanyak 12 data implikatur yang termasuk ke dalam makna implikatur. Hasil analisis wujud dan makna implikatur dalam humor Miss Dakem Karawang ini dapat dimanfaatkan sebagai bahan ajar teks anekdot untuk siswa SMA kelas $X$ yang disusun ke dalam handout. 
Ria Sonia, Oding Supriadi, Sahlan Mujtaba

Bentuk dan Makna Implikatur dalam Humor Miss Dakem Karawang serta Alternatifnya sebagai

Bahan Ajar Teks Anekdot di SMA Kelas $X$

\section{Daftar Pustaka}

Abdullah, S. N., \& Nurhidayah, Y. (2019). Analisis Semiotik Strategi Dakwah Humor Akun Instagram Nunuzoo. ORASI: Jurnal Dakwah Dan Komunikasi, 10(1), 115. doi:10.24235/orasi.v10i1.5145

Andriani, R. (2021). Implikatur dalam Wacana Pojok "Nuwun Sewu" pada Surat Kabar Harian Solopos Edisi Oktober 2019. Lingua Franca:Jurnal Bahasa, Sastra, dan Pengajarannya, 5(1), 70. doi:10.30651/lf.v5i1.5172

Arikunto, S. (2006). Metode Penelitian Kualitatif. Jakarta: Bumi Aksara.

Budiyanto, D. (2013). Penyimpangan Implikatur Percakapan dalam Humor-Humor Gus Dur. Litera, 8(2). doi:10.21831/ltr.v8i2.1206

Edi, S. (2018). Etnopragmatik Bingkai Kebudayaan Jawa pada Tuturan Kiai Jawa. Jawa Tengah: CV. Sarnu Untung.

Faizah, A. R. N. \& Rustono, R. (2017). Implikatur dalam Wacana Stand Up Comedy Indonesia Sesi 4 Dodit Mulyanto di Kompas TV. Jurnal Sastra Indonesia https://journal.unnes.ac.id/sju/index.php/jsi/article/view/16904

$6(1)$

Isnaniah, S. (2018). Analisis Implikatur Percakapan dalam Pembelajaran pada $\begin{array}{llll}\text { Mahasiswa IAIN Surakarta. SeBaSa, } & 135 .\end{array}$ doi:10.29408/sbs.v1i2.1041

Nugroho, D. A. D. (2020). Analisa Pragmatik Pelanggaran Maksim Percakapan dalam Iklan Mie Sedaap: Sebagai Proses Kreatif Pembuatan Iklan. Jurnal Komunikasi Profesional, 4(1). doi:10.25139/jkp.v4i1.2552

Pudyastuti, L. A. \& Zamzani, Z. (2019). Implikatur Percakapan dalam Pembelajaran Bahasa Indonesia di Sekolah. Widyaparwa, 47(1), https://widyaparwa.kemdikbud.go.id/index.php/widyaparwa/article/view/316

Rahayu, R., \& Markhamah, M. (2018). Implikatur Konvensional dalam Acara Stand Up Comedy Indonesia Season 7 di Stasiun Kompas TV. Doctoral Dissertation, Universitas Muhammadiyah Surakarta.

Sekarwati, S. H. (2018). Analisis Pelanggaran Maksim sebagai Strategi Pengungkapan Humor dalam Video Humor di Akun Instagram Ria Yunita. Sirok Bastra, 4(2), 138. doi:10.37671/sb.v4i2.83 
Ria Sonia, Oding Supriadi, Sahlan Mujtaba

Bentuk dan Makna Implikatur dalam Humor Miss Dakem Karawang serta Alternatifnya sebagai Bahan Ajar Teks Anekdot di SMA Kelas $X$

Tarigan, H, G. (2015). Pengajaran Pragmatik. Bandung: PT Angkasa.

Wahyuningsih, H., \& Rafli, Z. (2017). Implikatur Percakapan dalam Stand Up Comedy 4. Bahtera: Jurnal Pendidikan Bahasa dan Sastra, 16(2), 139153. https://doi.org/10.21009/BAHTERA.162.09

Yuliansyah, B. (2019). Jenis dan Fungsi Implikatur pada Buku Tuhan pun Berpuasa Karya Emha Ainun Nadjib. Doctoral dissertation, Universitas Muhammadyah Purwokerto.

Silampari Bisa: Jurnal Penelitian Pendidikan Bahasa Indonesia, Daerah, dan Asing Vol. 4, No. 2, 2021 